\title{
Behavioural and social sciences to enhance the efficacy of health promotion interventions: redesigning the role of professionals and people
}

\author{
FRANCESCA PENNUCCI* \\ Laboratorio Management e Sanità, Institute of Management and Department EMbeDS, Scuola Superiore \\ Sant'Anna, Pisa, Italy \\ SABINA DE ROSIS \\ Laboratorio Management e Sanità, Institute of Management and Department EMbeDS, Scuola Superiore \\ Sant'Anna, Pisa, Italy
}

ANNA MARIA MURANTE

Laboratorio Management e Sanità, Institute of Management and Department EMbeDS, Scuola Superiore Sant'Anna, Pisa, Italy

SABINA NUTI

Laboratorio Management e Sanità, Institute of Management and Department EMbeDS, Scuola Superiore Sant'Anna, Pisa, Italy

\begin{abstract}
Evidence on the effectiveness of health promotion interventions is mixed, especially in terms of the magnitude of their impact and long-term adherence. This paper proposes a comprehensive approach informed by behavioural economics of developing behavioural change programmes, which is designed to educate, activate, engage and empower people by taking into consideration individual and social mechanisms. Three applied pilots and their results are presented in order to illustrate the approach using cognitive and social mechanisms to lead to better health outcomes, individually and community-wide. More research is needed to explore levers and barriers for the systemic adoption of this framework in implementing health promotion interventions.
\end{abstract}

Submitted 22 May 2019; revised 28 May 2019; accepted 5 June 2019

\footnotetext{
* Correspondence to: Francesca Pennucci, Laboratorio Management e Sanità, Institute of Management and Department EMbeDS, Scuola Superiore Sant'Anna, 56127 Pisa, Italy. Email: f.pennucci@santannapisa.it
} 


\section{Introduction}

Population ageing, chronic diseases and unhealthy lifestyles are among the greatest challenges governments have to address. It is estimated that the older population, which in 2015 represented $8.5 \%$ of the world population (617.1 million), will double in the next 25 years (He et al., 2016). About $20 \%$ of the European population is aged 65 and over (OECD/EU, 2018). As people live longer, they are more likely to develop chronic diseases, which result in deaths that are "double that of all infectious diseases, maternal and perinatal conditions, and nutritional deficiencies combined" (WHO, 2005). Being overweight and obese are recognized as major risk factors for diabetes, cardiovascular diseases and cancer. The prevalence of obesity has increased globally (Malik et al., 2013) and in almost all European countries since 2000 (OECD/EU, 2018). The rate of increase among the young is higher than among adults (Lobstein et al., 2004; Wabitsch et al., 2014; GBD 2015 Obesity Collaborators, 2017). It is estimated that $23 \%$ of adults and $81 \%$ of adolescents in the world are not sufficiently active (WHO, 2018) and that dietary habits are unhealthy and inappropriate, especially in families of low socioeconomic status. Despite efforts in the health promotion and prevention fields, societies still need more protection from preventable diseases (OECD/ EU, 2018) by promoting healthy lifestyles and supporting people in managing their health and disease.

Evidence on the effectiveness of the existing interventions aimed at changing individual behaviour is mixed (Davis et al., 2015; Matjasko et al., 2016; Laverack, 2017). There are concerns over the magnitude of the impact on populations as a whole and individual adherence to programmes, especially following the termination of interventions (Middleton et al., 2013; De Poli et al., 2018). Changing behaviour is typically a complex process requiring continuous individual engagement over a long period of time (Prochaska et al., 1992; Bowles, 2016; Matjasko et al., 2016). There are proposals to use behavioural economics (BE) tools to improve the design, implementation and efficacy of public health interventions (Cialdini et al., 2015; Matjasko et al., 2016; Public Health England, 2018). In fact, BE recognizes the limitations of the classical rational choice model of individuals' behaviour (Just \& Payne, 2009; Thaler \& Sunstein, 2009; Kahneman, 2012).

To enhance the efficacy of preventative interventions directed towards behavioural change, the 'nudge' approach of Thaler and Sunstein is popularly seen to be what BE can offer. 'Nudges' are actions aimed at changing the choice architecture of individuals, making the 'right' choices more appealing to 'quick thinking' (Kahneman, 2012) than the 'wrong' ones. From 2010, the UK Behavioural Insights Team has worked to apply this method in several 
public domains, collecting evidence on the effectiveness of the proposed approach. Researchers have begun developing and specifying how and when it is proper to apply nudges. In particular, Oliver (2013) showed that the work of Nudge Units could be categorized along three different continuums: liberty of action; behavioural or rational model of reference; and orientation towards tackling internalities or externalities related to the targeted behaviours. Three categories of actions result from this analysis: 'nudges' (as above); 'shoves', which are more forceful than 'nudges' and imply explicit regulations limiting individuals' behaviour (e.g., a ban on selling sugary beverages inside schools); and 'budges', which are regulatory interventions aimed at reducing negative externalities that result from individual choices (e.g., regulating cigarette advertising to avoid consumer manipulation; Oliver, 2013, 2015). The first two are based on a paternalistic approach that represents the belief that it is possible "to motivate behaviour change among those who, on reflection, would have liked to have made different choices for themselves" (Oliver, 2015). Nudges and shoves generally address internalities (i.e., choice-related benefits for the individual who chooses), while budges are built to avoid the negative externalities resulting from incorrect individual behaviours (e.g., to avoid the burden of cost of managing choosers' obesity at the system level; Oliver, 2015).

$\mathrm{BE}$ tools tend to focus on individual cognitive biases rather than cultural orientation and social network dynamics (Leggett, 2014; Davis et al., 2015; Van Der Linden, 2018), which constantly influence people's choices (Boudon, 1981; Bourdieu \& Passeron, 1990; Weber, 1999; Täube, 2004; Barden, 2015). Adding this broader perspective to the redesign of preventative interventions can enhance their effectiveness (Cialdini et al., 2015; Public Health England, 2018; Van Der Linden, 2018).

\section{Redesigning services and the actors' role}

This paper proposes a framework with principles that are useful for improving the design and implementation of health promotion and preventative interventions in terms of the magnitude and duration of their impact (Figure 1). An alternative model of managing health promotion services and practices is proposed on the basis of a rethinking of the roles of health professionals and people in general, based on a collaboration between them.

The authors propose that improving health outcomes and creating broader individual and collective value from preventative actions require a programme organized around behavioural and social mechanisms and inspired by some or all the principles of education, activation, engagement and empowerment. 


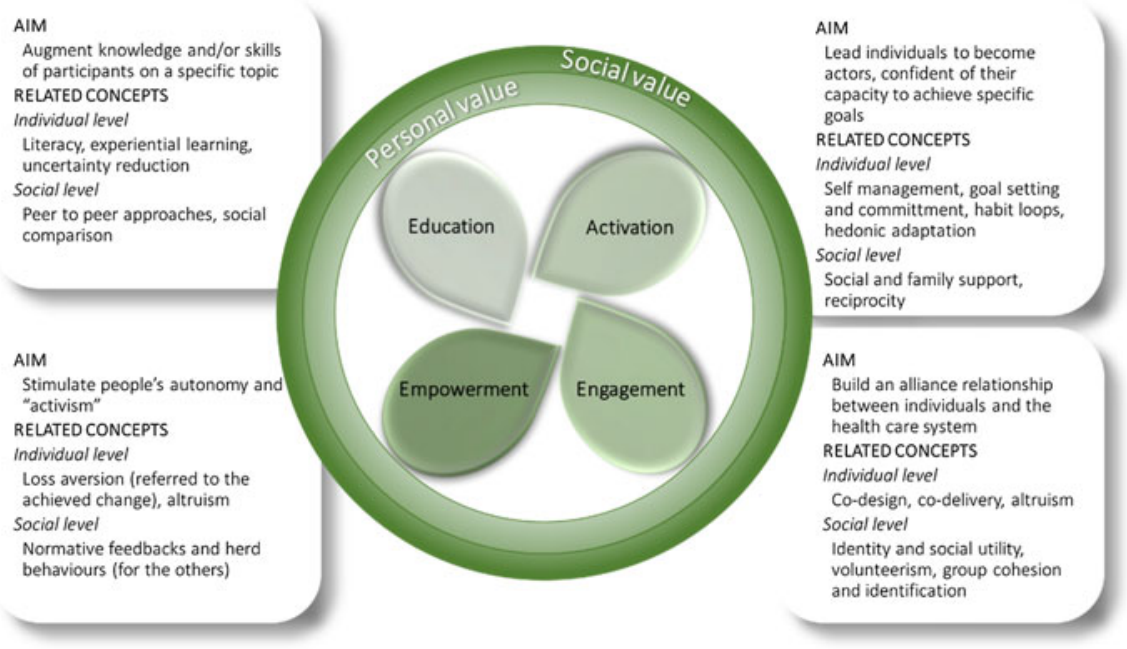

Figure 1. Framework for improving the design and implementation of health promotion and preventative interventions.

The aim of education is to increase people's amount of knowledge and/or skills. To be effective, it needs to be more than simply about conveying information passively (Middleton et al., 2013; Laverack, 2017), such as experiential and social learning (Knowles, 1989; Dudley et al., 2015). It has been demonstrated that group-based interventions are more effective than individualbased ones, even when participants expressed their preference for individual treatments (Middleton et al., 2013). Education also needs to be designed to make people aware of their cognitive limits and to teach them how to counteract such limits (Battersby \& Bailin, 2013; Croskerry, 2013).

Active individuals develop confidence in their capacity to achieve health goals (Hibbard et al., 2007) and achieve positive outcomes in health interventions more often (Mosen et al., 2007); this includes the efficient and appropriate use of resources, improvements in quality of care, etc. (Hibbard \& Greene, 2013; Lorig et al., 2016a). Furthermore, active individuals have greater awareness of their sociocultural context and are therefore able to better control day-to-day behaviours, in addition to self-management, commitment to applying practical knowledge and sticking to pursuing behavioural goals. Professionals can enable this process of activation through social mechanisms, such as through social learning and peer influences or raising awareness of social responsibility stemming from the broader consequences of an individuals' behaviour (Cialdini et al., 2015). 
Engagement involves building strong relationships among individuals and with the health care system (NICE, 2016). For example, professionals could collaborate with past participants of interventions to improve their design and deliver them together (i.e., past participants would act as peer workers or peer promoters). These practices of co-design and co-delivery are among the most effective ways of engaging laypeople in active participation (Bovaird \& Loeffler, 2014; Osborne et al., 2016; Vink et al., 2016). Engagement can be enhanced by using mechanisms such as identity and social utility, goal framing and pre-commitment to feel involved and willing to invest time and energy in actively participating (Samson, 2015).

Empowerment builds autonomy and 'activism' (Wallerstein, 1993; De Vos et al., 2009). The idea is that the appraised knowledge, the collected experiences and the social networks that have been developed become resources that participants will rely on to maintain the effort required to improve their habits and to participate in community actions. The increased sense of control enhances the diffusion of 'positive' herd behaviours and habits at the community level. Therefore, participants in health promotion interventions can become members of social networks that encourage them to continue adhering to the programme, to sustain them and to contribute to their redesign (Wallerstein, 1993).

In an ideal process, which would go from a first phase of education to a fourth and final stage of empowerment in a 'linear' fashion, professionals help participants understand what knowledge is needed to become active and engaged in the system, to feel empowered and to maintain what they have learned in their everyday lives (Middleton et al., 2013). However, in actuality, these four phases and principles are not mechanically applied to the interventions, which are designed with some phases either collapsed or skipped. Indeed, people are often involved in only one or two of the four phases of the ideal framework.

This paper presents three action research projects (Adelman, 1993; Whitehead et al., 2003) as examples of reframing a health promotion intervention to work better in terms of impact and adherence over time by paying attention to social and cultural elements in well-identified target populations: teenagers (Case 1); chronic patients (Case 2); and elderly people (Case 3). The specific overall goals of each intervention were: promotion of healthy lifestyles in Case 1; self-management of type 2 diabetes in Case 2; and promotion of physical activity in Case 3. The three experiences were implemented in Italy, mainly by the Tuscany Regional Health System (TRHS), with the collaboration of Laboratorio Management e Sanità (Pisa, Italy) research teams.

In the last 10 years, the region of Tuscany has put considerable effort into promoting healthy behaviours across its population with targeted campaigns 
and interventions directed at improving the management of chronic patients by adopting the Chronic Care Model (Wagner, 1998; Glasgow et al., 2001). At the local level, three Local Health Authorities (LHAs) are in charge of the health promotion/prevention and care for Tuscany's 3.7 million inhabitants. Health promotion is a responsibility of the local Department of Prevention of each LHA, and chronic care is delivered by general practitioners (GPs), who act as both the patients' gatekeepers to specialist care and the providers of primary care (including health promotion and prevention, as well as follow-up of chronic conditions). GPs are not employees of the TRHS, but work as independent contractors; they are generally paid by capitation.

\section{The beFood case}

In the Italian population aged from 2-19 years, obesity affects $7.24 \%$ of males and $5.86 \%$ of females, and the prevalence rates of being overweight are $21.00 \%$ and $16.75 \%$, respectively (GBD 2015 Obesity Collaborators, 2017). In 2015, the proportion of overweight adolescents in Tuscany was more than 12\% (Agenzia Regionale di Sanità della Toscana, 2015). Obesity in younger populations has increased in the last 10 years by $1.5 \%$, affecting $3.1 \%$ of Tuscan teenagers.

In response to these increases in prevalence, several policies have been adopted to prevent the young population from becoming obese and overweight. There is, however, contradictory evidence regarding the effectiveness of interventions targeted at young people (Wijtzes et al., 2017). This is because social environment- and network-related factors appear to be crucial in reaching the goals of initiatives aimed at preventing obesity (Wang Y. et al., 2013; Wang M. et al., 2014). There is some preliminary evidence on the effectiveness of peer influence, peer support and peer education in promoting health-related behaviours for young people (Lau et al., 1990; Borsari \& Carey, 2001; Salvy et al., 2012; Tolli, 2012; Jenkinson et al., 2014; Whipp et al., 2015; Aceves-Martins et al., 2017). Internet- and innovation-based initiatives, as well as programmes that appeal to adolescents, may also enhance the effectiveness of preventative interventions by improving healthrelated behaviour change (Whittemore et al., 2013; Chen \& Wilkosz, 2014; Aceves-Martins et al., 2017).

New models of intervention for promoting health and healthy lifestyles among children and adolescents have been recently tested in Tuscany. These models use behavioural and social mechanisms to enhance traditional interventions, which are often delivered in educational environments. The 'beFood' project was an action research project within a mandatory work-related learning pathway for high school students, called 'Alternanza Scuola-Lavoro' 
(ASL). The ASL projects provide students with professional opportunities and train them for a specific job according to their preferences and attitudes.

The main aim of the beFood project was to involve a group of forty-nine 16and 17-year-old students in peer-to-peer action research. Their 'job' assignment was to inform their peers about healthy lifestyles by conducting a large-scale participatory survey within the ASL programme.

In the first phase, the 49 students took part in a training and educational week outside of their schools. A peer-to-peer and digital-based method was adopted to build a dialogue with adolescents regarding their habits and preferences related to nutrition, physical activity and sports. In addition, they examined a range of influences on unhealthy behaviours (e.g., food marketing, techniques for framing default choices, present and habit loop biases) and analysed communication preferences (e.g., preferred sources of information), environmental aspects, self-esteem and self-perception.

The education phase was based on a collaborative approach focused on a pathway that put the students at the heart of the learning process and thus helped them to better retain and internalize the contents (Knowles, 1989). Experts and researchers actively involved students in practical activities aimed at 'learning by doing', nudging them to make healthier choices in terms of nutrition, sports and physical activity. The high school students were engaged in research topics, such as helping the researchers validate the questionnaire and test the web app used for administering the survey. The web-based survey was developed as a 'test' of each teenagers' lifestyle, which ended by providing a cartoon profile with suggestions for improving their habits by activating mechanisms of informational feedback, warnings and past choices (Eysenbach \& Wyatt, 2002; Sunstein, 2014; Samson, 2015). The teenagers were divided into ten groups (one for each Tuscan province) to improve peer group pressure and team-working skills and to stimulate competitive and collaborative mechanisms among them. During this first week, researchers consistently explained the importance of the students' role in the beFood research project to leverage mechanisms such as identification, increasing salience and building on social utility (Cialdini et al., 2015; Samson, 2015). The students were made aware that their work was fundamental to spreading the new knowledge they learned and that the dissemination of the 'healthy message' could improving their peers' lifestyle. They understood the importance of producing robust research results in order to have a concrete effect on lifestyles and inform policy-makers. A survey showed that almost $80 \%$ of the students completely agreed that the project provided them with knowledge and competency in adopting a healthy lifestyle. More than $73 \%$ completely agreed they had acquired a greater awareness of the 'value of the research' in public policy-making. The 49 students were informed that the last phase 
of the project included their presentation of the completed research and of the project's results directly to Tuscan policy-makers. These two aspects of responsibility and accountability towards official representatives were fundamental in empowering the students for the second phase of the project (Nuti et al., 2017).

In the second phase, the students were engaged in peer-to-peer interactions aimed at amplifying the magnitude of the impact of the intervention throughout the region. By applying what they had learned in the previous training week and with the support of their tutors, each of the ten groups was assigned the responsibility of informing a minimum sample of peers within their respective province of residence about healthy lifestyles. They chose how to accomplish the task using the beFood web app, which counted the numbers exposed to beFood messages and enabled easy participation by their peers in the beFood survey. Over 4 months, 5029 people completed the survey using the beFood web app, of which 4749 were 16- and 17-year-olds. These data were used to analyse teenagers' habits and preferences. The preliminary results were included into a report (Nuti et al., 2017). In the final phase of the project, the same 49 students presented the results to policy-makers, high school principals and teachers, researchers and experts.

Almost $70 \%$ of the 49 students gave a positive or very positive evaluation of the task they had been given, and $80 \%$ of them assessed the responsibility linked to this task as positive or very positive. Almost $59 \%$ of the students felt that they were a key part of the initiative. Two out of five reported that the influence their work had on their peers' lifestyle-related behaviours may have been significant. Half of the students reported having paid greater attention to nutrition and $30 \%$ to physical activity and sports. One out of four students had also given advice for a better lifestyle regarding nutrition on their own initiative, and $22 \%$ did so with regard to physical activity and sports. Almost $44 \%$ offered advice to peers who were friends, and more than $30 \%$ offered advice to their adult relatives.

Fifty-four percent of the participants stated that they had improved their nutrition-related behaviours after having participated in beFood, and $48 \%$ had improved their regularity in performing physical activities.

A short survey was sent to the respondents contacted by the students using the beFood web app. This second questionnaire has been answered by 147 teenagers. More than half of them $(51.5 \%)$ reported their intention to change their food-related behaviours, and $20.5 \%$ intending to change their physical activity habits after reading the beFood feedback. Four out of ten respondents indicated an improvement in their lifestyle behaviours. Sixty percent of those who had expressed intentions of changing their lifestyle reported having done so. 


\section{The Diabetic Patients' Self-Management case}

For diabetes, self-management is vital. In 2014, the Funding Program of the Italian Center for Disease Control, a department of the Italian Health Ministry, allocated a grant to three Italian Regional Health Systems: the autonomous province of Bolzano and the regions of Tuscany and Basilicata. They were willing to systematically implement an education programme for diabetes under the coordination of the Laboratorio Management e Sanità. The main aim of the Diabetic Patients' Self-Management (DPSM) programme was to promote healthy behaviours (diet and physical activity) through self-management in order to achieve an improvement in the health of diabetic patients.

The DPSM created by the Stanford Patient Education Research Center (Lorig et al., 2016a, 2016b) was adopted for educating patients. The programme aims to promote competencies in the three tasks involved in self-managing the disease (therapeutic management, which includes lifestyle; management of emotions; and management of the social role). The seminars are structured in six workshops each having a duration of 2.5 hours and delivered interactively, including goal-setting and reinforcement practices, to enhance individuals' self-efficacy (Bandura, 1997; Samson, 2015). This design has been tested in a Spanish version, but implementation takes context into account (Lorig et al., 2009). For the Italian version, the contents have been adapted by including reference to the Mediterranean diet pattern in order to foster participants' identification with the programme and to give consideration to specific cultural habits. The workshops are conducted in small groups (about 14-16 patients per group) either by health professional leaders or by trained lay leaders.

DPSM programme received strong support from each of the three Italian regions involved on the basis of its value in engaging and empowering patients themselves and their communities. In each region, laypeople, enrolled either from the community or from diabetes patient associations, were trained to be 'expert patients' and to lead a diabetes education programme. They were in charge of organizing and leading the six meetings and giving support to participants in need, either individually or assisted by a health professional.

A total of 76 seminars were held throughout the three regions, facilitated by 108 leaders and involving 909 diabetics and 72 caregivers. The seminars covered self-management, diet, physical activity, managing diabetes symptoms, self-efficacy and depression. Participants were on average 67 year of age and had, on average, 9.6 years of education. More than the half were men $(54 \%)$.

After 6 months of seminars, when a problem occurred, participants felt more confident in managing their disease at home most of the time: the self-efficacy score changed from 6.4 to $8.0(\mathrm{p}<0.0001)$. As a consequence, participants 
modified their diets (e.g., they reduced consumption of red meat and increased that of fish), spent more time walking and improved their adherence to prescribed drugs. In addition, participants showed a reduction in their number of visits to their doctors (hospital specialist or family doctor; $\mathrm{p}<0.0001$ ), as well as the use of hospitals and emergency departments (not statistically significant).

After 6 months of seminars, improvements in participants' health status were noted (reductions in the HbA1c indicator and body mass index $(\mathrm{p}<$ $0.0001)$ and depression scores $(\mathrm{p}<0.01))$. The expert patients who were peer instructors reported higher scores on self-sacrifice motivation, intrinsic motivation and sense-making. Participants gave positive feedback in terms of both the involvement of the lay leaders and their effective support during the programme.

At the end of the pilot project, each Regional Health System sought to include the education programme as part of their diabetes patient care pathways. Systemic strategies have been adopted (e.g., the Tuscany programme called IDEA - 'Incontri di educazione all'autogestione' ('Self-management education workshops for chronic patients')) to promote community engagement in the education programme and to achieve patient and family activation and empowerment.

\section{The Adapted Physical Activity case}

Population ageing means more people have chronic diseases and comorbidities (He et al., 2016). About a third of people living in Tuscany are physically inactive (Istituto Superiore di Sanità, 2016), with pernicious effects for those suffering from chronic diseases due to social exclusion, loss of autonomy and poor quality of life (Greaves and Farbus, 2006; James et al., 2011; He et al., 2016). The aim of promoting healthy lifestyles for people who are ageing is to increase physical activity levels by providing interventions that also tackle social exclusion and its consequences (Benvenuti, 2009; Speroni et al., 2011; Lim et al., 2012; Vainieri et al., 2016).

In 2005, Adapted Physical Activity (APA; in Italian, AFA) has been tested in Tuscany with the aim of giving elderly people a way to become and stay active in a safe context. The experience was a success and, over time, it has become a diffused and effective intervention throughout the region (Stuart et al., 2009; Ministero della Sanità, 2011; Songthai et al., 2014; Rachlis et al., 2016).

The APA programme is a community-based, progressive, supervised group exercise programme adapted to chronic alterations of functional status for the prevention and mitigation of disability (Stuart et al., 2009; Benvenuti, 2014). This programme is based on the Chronic Care Model (Wagner, 
1998), allowing people to stay together and to take care of their own physical and mental health by building effective networks of social support (Consiglio Regionale Toscana, 2008; Giunta Regione Toscana, 2009; Early Action Task Force, 2014).

APA is offered as a social rather than clinical activity and facilitates adults taking part in regular exercise through a social learning model (Sofi et al., 2011). Conventional preventative interventions (e.g., physiotherapy sessions) are limited in duration and treat participants as passive recipients. These characteristics lead to low adherence in patients continuing to exercise at home (Sofi et al., 2011; Litt et al., 2002). Instead, the APA programme is based on regular attendance by participants who are responsible for performing the exercises at home. During the weekly lessons, trainers provide participants with experiential knowledge on how to exercise, thus working to create a habit that becomes easy to sustain. Adherence is stimulated by social support developed through building and maintaining local social networks (Middleton et al., 2013). Being part of a social group context means participants can support each other in following instructions, in attending the sessions regularly and in repeating exercises at home (Sofi et al., 2011; Litt et al., 2002).

At the 6-month follow-up, a controlled study of the APA programme found that "the intervention group improved whereas controls declined in gait velocity, balance, Short Physical Performance Battery, and Stroke Impact Scale social participation domains" (Stuart et al., 2009). The depression score of participants improved by an average score of $4.4(\mathrm{p}<0.003)$, while people in the control group did not move from their baseline scores. Adherence and distance are highlighted as essential factors in achieving positive outcomes at the end of the programme (Sofi et al., 2011; Hicks et al., 2012). Indeed, ensuring that the assimilated habits are maintained over time and that local contexts are organized to guarantee access to the programme are fundamental to achieving beneficial and sustained outcomes.

After a successful pilot conducted in the LHA of Empoli, the programme was extended to the whole region, thus becoming a systemic action. To ensure easy access throughout Tuscany, APA providers can be either for-profit or nonprofit, and the activities can take place wherever is accessible and suitable (e.g., gyms, churches, buildings of political parties and local associations, municipalities). Groups of volunteers guarantee access by providing transportation where necessary. Every May, an 'APA day' is organized at the regional level with the aim of promoting participation in the programme through social and recreational activities (e.g., 'the healthy walk' or listening to previous participants' personal experiences). The activities are open to all.

After 10 years, the APA programme has become an established intervention with mass participation of 30,000 people throughout Tuscany (Vainieri et al., 
2016). This high rate of uptake is the result of various social influences (peerto-peer word of mouth, me-too processes, social reputation), the availability of the programme locally in familiar settings (e.g., gyms, theatres, churches) and the assistance provided to those in need of transportation. Those who take part in APA courses become members of active local social groups, which remedies loneliness and improves health (Stuart et al., 2009; Hicks et al., 2012), improving their happiness, empowerment and self-confidence, while providing a means to make use of underemployed spaces (i.e., in otherwise empty gyms in the morning).

\section{Results}

Table 1 shows the results of the three case studies compared on the basis of the education, activation, engagement and empowerment principles. In this section, the authors describe common and divergent elements pertaining to the three cases.

Education always took place in small groups in which individuals practiced the new habits ('by doing') through a participatory and engaging approach facilitated by peer interactions and laypeople. Education and communication strategies were aimed at supporting learning processes by increasing the salience of healthy messages and motivating participants towards their internalization. The educators/trainers created conditions for participants to be involved in first-hand experiences so that the subsequent behavioural change would be more effective than that of the traditional curricula (Knowles, 1989; Prochaska et al., 1992; Dudley et al., 2015; Samson 2015). Each educational intervention was developed based on participants' knowledge, experience and level of ability, thereby improving their self-confidence and sense of responsibility for their own health and quality of life. The new skills and knowledge were translated into a positive change of behaviour, which became a positive example for their networks of friends and relatives. In the beFood and DPSM experiences, laypeople were explicitly trained to become trainers of and messengers for their peers. In the APA case, only experts conducted the lessons. However, in all three cases, participants became advocates, messengers and testimonials of their healthy choices, especially in the beFood and APA cases, where the effect is amplified in terms of lifestyle-related behaviours. Each intervention activates three levels of social 'nudges' to encourage movement to healthier choices (Van Der Linden, 2018). Experts and laypeople 'nudge' participants; participants 'nudge' their peers and networks of friends and family; and changes in practice to the choice architecture nudge those who have not been involved. 


\section{Table 1. Comparative scheme of the implemented framework in the three case studies.}

\begin{tabular}{|c|c|c|c|}
\hline Dimension & beFood & DPSM & APA \\
\hline Education & $\begin{array}{l}\text { One-week training } \\
\text { course on healthy life- } \\
\text { style with experts and } \\
\text { peers, using participa- } \\
\text { tory teaching methods }\end{array}$ & $\begin{array}{l}\text { Six weekly seminars of } \\
2.5 \text { hours delivered in } \\
\text { small groups and led by } \\
\text { laypeople or profes- } \\
\text { sionals (nurses, dieti- } \\
\text { cians, expert patients) }\end{array}$ & $\begin{array}{l}\text { Two days per week to } \\
\text { learn simple and safe } \\
\text { physical exercises, to be } \\
\text { executed both during the } \\
\text { course and at home }\end{array}$ \\
\hline Activation & $\begin{array}{l}\text { Participants take on } \\
\text { responsibility for: }(1) \\
\text { their lifestyle and its } \\
\text { future outcomes on } \\
\text { their health; (2) the } \\
\text { specific measurable } \\
\text { target to reach in the } \\
\text { professional (and man- } \\
\text { datory) pathway of } \\
\text { 'Alternanza Scuola- } \\
\text { Lavoro' }\end{array}$ & $\begin{array}{l}\text { Participants improve } \\
\text { their feeling of being } \\
\text { self-effective. When a } \\
\text { problem occurred, they } \\
\text { felt more confident most } \\
\text { of the time in managing } \\
\text { their disease at home. } \\
\text { Additionally, lay } \\
\text { leaders are motivated to } \\
\text { support diabetes } \\
\text { patients in the educa- } \\
\text { tion process }\end{array}$ & $\begin{array}{l}\text { Participants take on } \\
\text { responsibility for their } \\
\text { health management. } \\
\text { Their specific role is to } \\
\text { participate regularly in } \\
\text { the programme, con- } \\
\text { tributing with a small } \\
\text { amount of money }\end{array}$ \\
\hline Engagement & $\begin{array}{l}\text { New competencies are } \\
\text { interiorized and parti- } \\
\text { cipants become mes- } \\
\text { sengers and } \\
\text { testimonials (advocacy } \\
\text { effect) }\end{array}$ & $\begin{array}{l}\text { Diabetes patients become } \\
\text { managers of their daily } \\
\text { lives and, when they are } \\
\text { confident about their } \\
\text { self-efficacy level, they } \\
\text { may also become lay } \\
\text { leaders or promoters of } \\
\text { healthy behaviours } \\
\text { among their relatives or } \\
\text { communities (collea- } \\
\text { gues, friends, etc.) }\end{array}$ & $\begin{array}{l}\text { Participants become sup- } \\
\text { porters of one another. } \\
\text { General practitioners, } \\
\text { local authorities and } \\
\text { associations work to } \\
\text { promote and spread the } \\
\text { courses, and also elim- } \\
\text { inating obstacles to } \\
\text { participation }\end{array}$ \\
\hline Empowerment & $\begin{array}{l}\text { Interiorized competen- } \\
\text { cies produce self- } \\
\text { awareness/conscious- } \\
\text { ness and are translated } \\
\text { into behavioural } \\
\text { changes (healthy food } \\
\text { choices and greater } \\
\text { physical activity). A } \\
\text { social nudge for parti- } \\
\text { cipants' networks is } \\
\text { activated }\end{array}$ & $\begin{array}{l}\text { The participants' active } \\
\text { role makes them able to } \\
\text { effectively manage their } \\
\text { health and behaviours } \\
\text { and to choose how to } \\
\text { appropriately use health } \\
\text { system resources. } \\
\text { Laypeople are empow- } \\
\text { ered to continue their } \\
\text { work for their } \\
\text { communities }\end{array}$ & $\begin{array}{l}\text { Participants' autonomy is } \\
\text { augmented, and they } \\
\text { become more aware of } \\
\text { the importance of self- } \\
\text { management. They can } \\
\text { now be testimonials of } \\
\text { the programme into } \\
\text { their networks }\end{array}$ \\
\hline
\end{tabular}


Table 1. (Cont.)

\begin{tabular}{|c|c|c|c|}
\hline Dimension & beFood & DPSM & APA \\
\hline $\begin{array}{l}\text { Personalized } \\
\text { and social } \\
\text { value }\end{array}$ & $\begin{array}{l}\text { Better lifestyle. } \\
\text { Spontaneous sugges- } \\
\text { tions/nudges to peers } \\
\text { and relatives on correct } \\
\text { behaviours for a } \\
\text { healthy lifestyle. } \\
\text { Voluntary support to } \\
\text { peers and relatives who } \\
\text { want to improve their } \\
\text { lifestyles }\end{array}$ & $\begin{array}{l}\text { Diabetes patients } \\
\text { improve their health } \\
\text { status (HbA1c and } \\
\text { body mass index), are } \\
\text { more confident and } \\
\text { effective in managing } \\
\text { their daily lives and } \\
\text { become performers of } \\
\text { health promotion inter- } \\
\text { ventions themselves in } \\
\text { their communities }\end{array}$ & $\begin{array}{l}\text { Improvement of both } \\
\text { physical and mental } \\
\text { health and reduced level } \\
\text { of isolation. Participants } \\
\text { have a reduced need for } \\
\text { rehabilitation. } \\
\text { Furthermore, there } \\
\text { might be a decrease in } \\
\text { their need for social } \\
\text { support and a greater } \\
\text { possibility of them } \\
\text { becoming a caregiver }\end{array}$ \\
\hline
\end{tabular}

The three interventions differ on the applicability of the four principles of education, activation, engagement and empowerment. The APA programme was first thought of simply as a clinical intervention with a small activity component for participants. However, the elements characterizing its activities transformed it into an innovative preventative intervention that increasingly enables participants to develop autonomy and responsibility in taking care of themselves and involving others. Participants are not involved in designing and delivering the APA intervention at an early stage, but they can participate in witnessing the programme in their networks. For beFood, the initial training week of the 49 students has been structured with overlapping education and engagement activities, involving simultaneous knowledge transfer and collaboration between researchers and teenagers in designing and conducting the intervention. DPSM works on education, activation and empowerment throughout the workshops, but engagement depends on the future availability of some participants to become lay or peer instructors.

\section{Discussion and conclusions}

The three experiences described in this paper show how health promotion interventions can be redesigned to exploit behavioural and social mechanisms in order to create the right conditions to make individuals, patients and communities able to improve their health and well-being and increase both individual and social value. In particular, the education-activation-engagement-empowerment 
framework has been tested as a way of implementing and analysing behaviourally and socioculturally informed interventions (see Figure 1).

The development of each intervention was not based on a mechanical application of the four principles of the framework. On the contrary, each includes specific features that meet the needs and preferences of the targeted population according to their sociocultural context, intervention goals and lessons learned from previous experiences. Two of the three cases, namely the DPSM and APA programmes, have detailed structures, have been repeatedly tested and are replicated at low cost. APA has shown its flexibility in different non-clinical settings and has succeeded in reaching large numbers of people in a short period of time, improving their health and quality of life. In contrast, beFood is a first explorative experience in drawing on digital technologies and collaborative processes to conduct a health promotion intervention, and so has yet to be replicated.

All three interventions have addressed the issues of magnitude of impact, adherence and social and cultural variables in behaviourally informed interventions. The attention paid to these aspects differentiates these programmes from conventional actions like as National Diabetes Preventive Programme. This national programme implemented in England is an example of a traditional preventative intervention that, even if it were cost effective, would prevent few of those who enrol in it from developing diabetes because of its limited impact on substantive and enduring behavioural change (De Poli et al., 2018).

Alternatively, experiential learning, social support and community engagement, the possibility of participants getting 'officially' engaged within the system's activities and empowerment can be key principles for enlarging the magnitude of impact of health promotion interventions. The implemented participatory group-based learning methods and the peer processes allowed each intervention to have a greater impact in terms of the number of people they 'touched', thanks to the active role of participants. Engaged and empowered participants have directly or indirectly reached a number of other people in their networks, becoming effective collaborators with the system by spreading the knowledge and skills they acquired during the education and activation phases. The APA participants' engagement with institutional activities is mostly informal and based on their voluntary initiative, but it has been very effective in building supportive networks that ensure long-term adherence following the termination of the intervention. Participants in DPSM activities can choose to be engaged in delivering the programme to future classes of diabetic patients, and their participation as lay leaders increases participants' satisfaction with the programme. Finally, students who participated in beFood gained early access to practical knowledge and were considered as protagonists of the project from the beginning, collaborating with researchers in the design 
and delivery of the intervention. Identification and peer comparison stimulated them to spread the beFood message to peers and relatives.

Adherence is also fundamental to maintaining behavioural changes over time (Middleton et al., 2013). The processes of education, activation, engagement and empowerment of individuals, implemented by the health services providers, laypeople and peers, coupled with the implied behavioural and social mechanisms, are essential for enabling and facilitating participants to continue after the intervention ends by enhancing adherence in their daily lives at both the individual and social levels. Social support and normative feedback dynamics were used to enhance people's long-term adherence to the newly established routines. The possibility of sharing everyday challenges with other participants leads to the creation of supportive social networks that can work, after the intervention ends, as 'extended care' structures (Middleton et al., 2013).

Each intervention has been developed specifically for the targeted population by taking into account the social and cultural dimensions influencing their behaviour. As Van Der Linden (2018) showed, this adds to the effectiveness of $\mathrm{BE}$ approaches directed at individuals by exploiting the power of social nudges. Indeed, redefining identity through social norms is a powerful mechanism that is easy to implement for changing behaviour (Cialdini et al., 2015). In this way, individuals develop a new health literacy to guide their actions in making their daily environments healthier.

The implementation of interventions similar to those described above implies a redefinition of health care professionals' role from providers to solutionfinders, context-makers or directors and supporters of people. Taking into consideration the patients' perspectives is not sufficient: the patients themselves should be actively involved and engaged at both the individual and community levels by working on the behavioural and social mechanisms that affect their motivation to change. This approach is based not on the traditional assumption of agency for the citizen, but on the acknowledgement of the active roles of different stakeholders in the entire process of health value creation. The concept of the patient-doctor relationship needs to be revised for preventative interventions by working on the behavioural and cultural dimensions and by changing the paternalistic educational approach to learning processes in order to give greater autonomy to people. This means health care professionals need to build the right conditions (i.e., choice architectures, social contexts, etc.) to engage and empower people by increasing or improving their knowledge and skills, building on their capabilities and nudging and supporting them in maintaining, advocating for and spreading new, healthier habits and knowledge. To this end, professionals need to recognize the potential roles of individuals, their networks and the benefits people can produce at the 
individual and collective levels. They also need to learn how to highlight the available individual and social resources for creating value in the specific action context in order to adapt and reshape the intervention design and implementation in terms of learning, enabling processes and contents. Health care services can create enabling contexts for designing interventions focused on useful behavioural and social dynamics in order to build, improve and support the knowledge, skills and motivation of people, thus allowing them to become the main actors in generating value at the individual and collective levels. The professionals' role changes from determining what might be valuable for passive recipients to coordinating and promoting individuals' participation, supporting behavioural changes and facilitating advocacy and reciprocity effects (Knowles, 1989; Middleton et al., 2013; Cialdini et al., 2015).

This proposal differs from the 'nudge' interventions that assume that the 'nudgers' know what are the best choices to propose. However, this vision can easily lead policy-makers to adopt a paternalistic approach (Matjiasko et al., 2016). In contrast, the three interventions described above have been built on a person-centred and person-driven model (Leggett, 2014; Oliver, 2015) based on collaborative processes and specific attention being paid to the cultural and social contexts (Middleton et al., 2013; Laverack, 2017).

\section{Acknowledgements}

The Region of Tuscany financed both the beFood and the APA projects. The Italian Minister of Health financed the DPSM project (CCM program).

\section{Author contributions}

All of the authors were involved in designing the overall contents of this paper, wrote the manuscript and were involved in interpreting the findings. In particular, all of the authors were responsible for writing the manuscript, with the following contributions on: introduction and discussion (SN, FP, AMM, SDR); theoretical background (FP); beFood case (SDR); DPSM case (AMM); AFA case (FP). All of the authors approved the final manuscript.

\section{References}

Aceves-Martins, M. et al. (2017), 'A School-Based, Peer-Led, Social Marketing Intervention to Engage Spanish Adolescents in a Healthy Lifestyle ("We Are Cool"- -Som la Pera Study): A Parallel-Cluster Randomized Controlled Study', Childhood Obesity, 13, 300-313. 
Adelman, C. (1993), 'Kurt Lewin and the Origins of Action Research', Educational Action Research, $1,7-24$.

Agenzia Regionale di Sanità della Toscana, (2015), Comportamenti alla guida e stili di vita a rischio nei ragazzi in Toscana, Florence, Italy: Agenzia Regionale di Sanità della Toscana.

Bandura, A. (1997), Self-efficacy: The exercise of control, Self-efficacy: The exercise of control, New York, NY, US: W H Freeman/Times Books/ Henry Holt \& Co.

Barden, P. (2015), From Branding to Action, in: A Samson. (Ed.), The Behavioural Economics Guide 2015 (with an Introduction by Dan Ariely), behavioraleconomics.com.

Battersby, M. and S. Bailin (2013), Critical thinking and cognitive biases. In: OSSA Conference Archive. Presented at the OSSA Conference, p. 10.

Benvenuti, F. (2014), 'Translating exercise and mobility interventions into community-based programs: The Italian adaptive physical activity program', Int J Stroke, 9, 2-15.

Benvenuti, F. (2009), Attività fisica adattata (AFA): che cos'è e a che cosa serve. Presented at the $37^{\circ}$ Congresso Nazionale SIMFER, Campobasso.

Borsari, B. and K. B. Carey (2001), 'Peer influences on college drinking: A review of the research', Journal of Substance Abuse, 13, 391-424.

Boudon, R. (1981), The Logic of Social Action, London; Boston: Routledge Kegan \& Paul.

Bourdieu, P. and J.-C. Passeron (1990), Reproduction in Education, Society and Culture, 2nd ed, SAGE Publications Ltd.

Bovaird, T. and E. Loeffler (2014), 'We're all in this together: User and community co-production of public outcomes', in: Making Sense of the Future: Do We Need a New Model of Public Services? Birmingham: INLOGOV.

Bowles, S. (2016), The Moral Economy: Why Good Incentives Are No Substitute for Good Citizens, New Haven; London: Yale University Press.

Chen, J.-L. and M. E. Wilkosz (2014), 'Efficacy of technology-based interventions for obesity prevention in adolescents: a systematic review', Adolesc Health Med Ther, 5, 159-170.

Cialdini, R. B., S. J. Martin and N. J. Goldstein (2015), 'Small behavioral science-informed changes can produce large policy relevant effects', Behavioral Science \& Policy, 1, 21-27.

Croskerry, P. (2013), 'From Mindless to Mindful Practice - Cognitive Bias and Clinical Decision Making', New England Journal of Medicine, 368, 2445-2448.

Davis, R., et al. (2015), 'Theories of behaviour and behaviour change across the social and behavioural sciences: a scoping review', Health Psychol Rev, 9, 323-344.

De Poli, C., et al. (2018), Why does a cost-effective behavioural change programme have a negligible impact on the projected epidemic of type 2 diabetes? Presented at the Wennberg International Collaborative Spring Policy Meeting, Zurich.

De Vos, P., et al. (2009), 'Health through people's empowerment: a rights-based approach to participation', Health Hum Rights, 11, 23-35.

Dudley, D. A., W. G. Cotton and L. R. Peralta (2015), 'Teaching approaches and strategies that promote healthy eating in primary school children: a systematic review and meta-analysis', International Journal of Behavioral Nutrition and Physical Activity, 12, 28.

Early Action Task Force (2014), Looking Forward to Later Life: Taking an Early Action Approach to Our Ageing Society, London: Community Links.

Eysenbach, G. and J. Wyatt (2002), 'Using the Internet for surveys and health research', J. Med. Internet Res, 4, E13.

GBD 2015 Obesity Collaborators (2017), 'Health Effects of Overweight and Obesity in 195 Countries over 25 Years', New England Journal of Medicine, 377, 13-27.

Giunta Regione Toscana (2009), DGR 459/2009, Attività Fisica Adattata (AFA). https://ec.europa.eu/ eip/ageing/sites/eipaha/files/practices/delibera_n.459_del_03-06-2009.pdf. 
Glasgow, R. E., C. T. Orleans, E. H. Wagner, S. J. Curry and L. I. Solberg (2001), 'Does the chronic care model serve also as a template for improving prevention? Milbank Quarterly, 79, 579_ 612, iv-v.

Greaves, C. J. and L. Farbus (2006), 'Effects of creative and social activity on the health and wellbeing of socially isolated older people: outcomes from a multi-method observational study', $J$ R Soc Promot Health, 126, 134-142.

He, W., D. Goodkind and P. Kowal, (2016), An Aging World: 2015 (No. P95-16-1). US Census Bureau.

Hibbard, J. H. and J. Greene (2013), 'What the evidence shows about patient activation: better health outcomes and care experiences; fewer data on costs', Health Aff, 32, 207-214.

Hibbard, J. H., et al. (2007), 'Do increases in patient activation result in improved self-management behaviors? Health Serv Res, 42, 1443-1463.

Hicks, G. E., et al. (2012), 'Adherence to a community-based exercise program is a strong predictor of improved back pain status in older adults: an observational study', Clin J Pain, 28, 195-203.

Istituto Superiore di Sanità, (2016), Sorveglianza Passi. http://www.epicentro.iss.it/passi/

James, B. D., et al. (2011), 'Relation of late-life social activity with incident disability among community-dwelling older adults', J. Gerontol. A Biol. Sci. Med. Sci, 66, 467-473.

Jenkinson, K. A., G. Naughton and A. C. Benson (2014), 'Peer-assisted learning in school physical education, sport and physical activity programmes: a systematic review', Physical Education and Sport Pedagogy, 19, 253-277.

Just, D. R. and C. R. Payne, (2009), 'Obesity: Can Behavioral Economics Help? Ann Behav Med, 38, s47-s55.

Kahneman, D. (2012), Thinking, Fast and Slow, Penguin Books Ltd.

Knowles, M. S. (1989), The making of an adult educator. An Autobiographical Journey. 1st ed, Jossey-Bass Inc., Publishers.

Lau, R. R., M. J. Quadrel and K. A. Hartman (1990), 'Development and change of young adults' preventive health beliefs and behavior: influence from parents and peers', $J$ Health Soc Behav, 31, 240-259.

Laverack, G. (2017), 'The Challenge of Behaviour Change and Health Promotion', Challenges, 8, 25. Leggett, W. (2014), The politics of behaviour change: nudge, neoliberalism and the state.

Lim, S. S., et al. (2012), 'A comparative risk assessment of burden of disease and injury attributable to 67 risk factors and risk factor clusters in 21 regions, 1990-2010: a systematic analysis for the Global Burden of Disease Study 2010', Lancet, 380, 2224-2260.

Litt, M. D., A. Kleppinger and J. O. Judge (2002), 'Initiation and maintenance of exercise behavior in older women: predictors from the social learning model', J Behav Med, 25, 83-97.

Lobstein, T., et al. (2004), 'Obesity in children and young people: a crisis in public health', Obes Rev, 5 (Suppl 1): 4-104.

Lorig, K., et al. (2016a), 'A Diabetes Self-Management Program: 12-Month Outcome Sustainability From a Nonreinforced Pragmatic Trial', J Med Internet Res, 18.

Lorig, K., et al. (2016b), 'Benefits of Diabetes Self-Management for Health Plan Members: A 6-Month Translation Study', J Med Internet Res, 18.

Lorig, K., et al. (2009), 'Community-Based Peer-Led Diabetes Self-management', Diabetes Educ, 35, 641-651.

Malik, V. S., W. C. Willett and F. B. Hu (2013), 'Global obesity: trends, risk factors and policy implications', Nat Rev Endocrinol, 9, 13-27.

Matjasko, J. L., et al. (2016), 'Applying Behavioral Economics to Public Health Policy: Illustrative Examples and Promising Directions', Am J Prev Med, 50, S13-S19.

Middleton, K. R., S. D. Anton and M. G. Perri (2013), 'Long-Term Adherence to Health Behavior Change', Am J Lifestyle Med, 7, 395-404. 
Ministero della Sanità Italiano (2011), Piano d'indirizzo per la riabilitazione, Rome, Italy: Ministero della Sanità Italiano.

Mosen, D. M., et al. (2007), 'Is patient activation associated with outcomes of care for adults with chronic conditions? J Ambul Care Manage, 30, 21-29.

NICE, (2016), Community engagement: improving health and wellbeing and reducing health inequalities, London, UK: NICE.

Nuti, S., et al. (2017), beFood, stili di vita a confronto. Ricette sperimentali per un futuro healthy degli adolescenti, Edizioni Il Campano, Ghezzano (PI).

OECD/EU (2018), Health at a Glance: Europe 2018: State of Health in the EU Cycle, Paris, France; Brussels, Belgium: OECD Publishing.

Oliver, A. (2015), 'Nudging, Shoving, and Budging: Behavioural Economic-Informed Policy', Public Administration, 93, 700-714.

Oliver, A. (2013), 'From Nudging to Budging: Using Behavioural Economics to Inform Public Sector Policy', Journal of Social Policy, 42, 685-700.

Osborne, S. P., Z. Radnor and K. Strokosch (2016), 'Co-Production and the Co-Creation of Value in Public Services: A suitable case for treatment? Public Management Review, 18, 639-653.

Prochaska, J. O., C. C. DiClemente and J. C. Norcross (1992), 'In search of how people change. Applications to addictive behaviors', Am Psychol, 47, 1102-1114.

Consiglio Regionale Toscana (2008), Piano Sanitario Regionale of Tuscany Region 2008-2010. http:// www.regione.toscana.it/documents/10180/400011/Piano+sanitario+regionale+2008+2010.pdf/ cf0a019a-9f3e-4fd8-92ad-5af69d7873f2.

Public Health England (2018), Improving people's health: applying behavioural and social sciences. GOV.UK. https://www.gov.uk/government/publications/improving-peoples-health-applyingbehavioural-and-social-sciences.

Rachlis, B., et al. (2016), 'Identifying common barriers and facilitators to linkage and retention in chronic disease care in western Kenya', BMC Public Health, 16, 741.

Salvy, S.-J., et al. (2012), 'Influence of peers and friends on children's and adolescents' eating and activity behaviors', Physiol. Behav, 106, 369-378.

Samson, A. (2015), The Behavioural Economics Guide 2015 (with an introduction by Dan Ariely). behavioraleconomics.com

Sofi, F., et al. (2011), 'Adaptive physical activity and back pain: a non-randomised community-based intervention trial', Eur J Phys Rehabil Med, 47, 543-549.

Songthai, N., et al. (2014), 'Effects of Peer-support, Self-management Program on Self-management Behavior and Blood Pressure of Older Adults with Essential Hypertension', Chiang Mai University Journal of Natural Sciences, 13.

Speroni, C., et al. (2011), 'La promozione della salute: una sfida per il management delle Aziende sanitarie', Politiche Sanitarie, 12, 13-21.

Stuart, M., et al. (2009), 'Community-based adaptive physical activity program for chronic stroke: feasibility, safety, and efficacy of the Empoli model', Neurorehabil Neural Repair, 23, 726-734.

Sunstein, C. R. (2014), Nudging: A Very Short Guide, Rochester, NY: Social Science Research Network.

Täube, V. (2004), 'Measuring the Social Capital of Brokerage Roles', Connections, 26, 29-52.

Thaler, R. H. and C. R. Sunstein (2009), Nudge: Improving Decisions About Health, Wealth, and Happiness, Updated edition, Ed. New York: Penguin Group USA.

Tolli, M. V. (2012), 'Effectiveness of peer education interventions for HIV prevention, adolescent pregnancy prevention and sexual health promotion for young people: a systematic review of European studies', Health Educ Res, 27, 904-913.

Vainieri, M., et al. (2016), Il Sistema di Valutazione della Performance della Sanità toscana - Report 2015, Laboratorio Management e Sanità. 
Van Der Linden, S. (2018), 'The future of behavioral insights: on the importance of socially situated nudges', Behavioural Public Policy, 2, 207-217.

Vink, J., et al. (2016), Understanding the Influence of the Co-Design Process on Well-Being. Presented at the ServDes 2016, Copenhagen.

Wabitsch, M., A. Moss and K. Kromeyer-Hauschild (2014), 'Unexpected plateauing of childhood obesity rates in developed countries', BMC Medicine, 12, 17.

Wagner, E. H. (1998), 'Chronic disease management: what will it take to improve care for chronic illness? Eff Clin Pract, 1, 2-4.

Wallerstein, N. (1993), 'Empowerment and Health: The Theory and Practice of Community Change', Community Development Journal, 28, 218-27.

Wang, M., et al. (2014), 'The Role of Social Support vs. Modeling on Adolescents' Diet and Physical Activity: Findings from a School-based Weight Management Trial', Journal of Child and Adolescent Behavior, 2, 1-6.

Wang, Y., et al. (2013), Childhood Obesity Prevention Programs: Comparative Effectiveness Review and Meta-Analysis, AHRQ Comparative Effectiveness Reviews, Rockville (MD): Agency for Healthcare Research and Quality (US).

Weber, M. (1999), Economia e società vol.1. Einaudi.

Whipp, P. R., et al. (2015), 'The effects of formalized and trained non-reciprocal peer teaching on psychosocial, behavioral, pedagogical, and motor learning outcomes in physical education', Front Psychol, 6.

Whitehead, D., A. Taket and P. Smith (2003), 'Action research in health promotion', Health Education Journal, 62, 5-22.

Whittemore, R., S. Jeon and M. Grey (2013), 'An internet obesity prevention program for adolescents', J Adolesc Health, 52, 439-447.

WHO (2005), Chronic diseases and their common risk factors, Geneva, Switzerland: WHO Press.

WHO (2018), Physical activity. https://www.who.int/news-room/facts-in-pictures/detail/physicalactivity.

Wijtzes, A. I., et al. (2017), 'Effectiveness of interventions to improve lifestyle behaviors among socially disadvantaged children in Europe', Eur J Public Health, 27, 240-247. 